\title{
Human resource management, Lean processes and outcomes for employees: towards a research agenda
}

\author{
Greg J. Bamber ${ }^{\mathrm{a}, \mathrm{b} *}$, Pauline Stanton ${ }^{\mathrm{c}}$, Timothy Bartram ${ }^{\mathrm{d}}$ and Ruth Ballardie $\mathrm{e}^{\mathrm{e}}$ \\ ${ }^{a}$ Department of Management, Monash University, Melbourne, Australia; ${ }^{b}$ Business School, \\ Newcastle University, Newcastle, UK; ' School of Management, RMIT University, Melbourne, \\ Australia; ${ }^{d}$ Department of Management, La Trobe University, Melbourne, Australia; ${ }^{e}$ College of \\ Business, Victoria University, Melbourne, Australia
}

\begin{abstract}
Lean management or lean thinking is a process improvement technique that along with Six Sigma is used in an increasing range of workplaces. This special issue focuses on the use of Lean in developed countries. This increased usage reflects a growing propensity for managers to launch initiatives to upgrade the efficiency and productivity of the enterprises that they manage, usually in an attempt to enhance the cost- effectiveness of operations. This special issue of the IJHRM includes eight articles in addition to this one on various aspects of the connections between lean management, human resource management (HRM) and outcomes for employees. The present article reviews the context for the increasing popularity of lean ideas among managers. Drawing on research in a range of countries, the articles in the special issue provide interesting insights into the relationships between process improvement innovations and HRM, as well as raise further important questions for research, which enable us to suggest an agenda for future research. This includes asking: what are the differences in the ways that Lean is implemented, for example the differences that may reflect industry, regional and national variables?
\end{abstract}

Keywords: human resource management; lean management; lean thinking; process improvement; research agenda

\section{Introduction}

In recent decades, there has been a growing use of Business Process Re-engineering and Process Improvement techniques around the world in different industries and national contexts. The publication of The Machinethat Changedthe World by Womack, Jones, and Roos (1990) led to renewed interest in production techniques that had their origins in the work, for instance, of Taylor (1911), Ohno (1978) and Deming (1986). This interest has reflected managers' drives for efficiency, productivity and more costeffective and high- quality outcomes for their stakeholders, including shareholders, managers and customers or clients. As Shah, Chandrasekaran, and Linderman (2008) observe, techniques such as Lean and Six Sigma in particular have gained popularity and there is a huge practitioner literature on the benefits of such processes and their links to improved performance.

Womack et al. (1990) celebrated the Toyota Motor Corporation and its iconic Toyota Production System, which was developed to cut costs and improve quality. This approach involved identifying and reducing non-value-adding process steps (Womack \& Jones, 2003). Following Womack et al. (1990), subsequent analysts referred to this also as Toyotism or Lean production (Holweg, 2007).

*Corresponding author. Email: gregbamber@gmail.com 
In trying to emulate Toyota's success, Toyotism was adapted and implemented by competing car manufacturers, as well as other manufacturing sectors and service industries. Those who adapted these process improvement techniques to contexts beyond manufacturing tended to use the term 'lean thinking' or simply Lean, as more generic terms to describe its more widespread application (Plsek, 2013).

Most of the early academic literature focused on manufacturing (Linehart, Huxley, \& Robertson, 1997; Shadur, Rodwell, \& Bamber, 1995; Stewart \& Garrahan, 1995; Womack \& Jones, 2003), since it was the automotive industry and other manufacturing that were the first to use Lean management and Six Sigma. However, as a range of other sectors, including service industries such as health care, have implemented Lean and Six Sigma, research has also extended into these areas (Bamber, Gittell, Kochan, \& von Nordenflytch, 2009; Ben-Tovim et al., 2007; Kollberg, Dahlgaard, \& Brehmer, 2007).

Shah et al. (2008, p. 6682) indicate that

both Lean and Six Sigma can be characterized in terms of their underlying philosophy and a set of practices, tools/techniques, implementation orientation, unit of analysis, and performance measures associated with them.

Arnheiter and Maleyeff (2005) define Six Sigma as a system of quality control to reduce the number of defective parts in complex devices to six standard deviations from the mean. Managers may use Six Sigma to supplement Lean approaches to assist in identifying and reducing variation. The purported benefits of Lean and Six Sigma include: increased quality and efficiency, reduced costs and a focus on customers' needs.

However, with regard to implementing Lean processes, Shah et al. (2008, p. 6683) distinguishes Lean as a 'bottom-up approach where management plays a supportive and facilitating role in engaging shop-floor workers to form cross- functional self-directed work teams and apply Lean tools'. By contrast, Six Sigma tends to be a top-down approach, where 'management plays a more active role selecting improvement projects based on financial and strategic goals, then championing and monitoring improvement projects' (p. 6683). This suggests different implications for the process of implementation within organisations. Proponents of Lean thinking argue that it shifts managerial intentions from optimising separate technologies, assets and vertical departments within traditionally silo-structured organisations to optimising the flow of products and services through value streams that flow horizontally across technologies, assets and departments to customers (Lean Enterprise Australia, n.d.).

In shifting to the deployment of Lean processes, managers face two sets of significant challenges: first, how to manage the implementation and impact of these initiatives most effectively at the organisational level and, second, how to ensure the longevity (sustainability) of such changes.

Compared to implementation processes and outcomes, the research on the effects of Lean on employees is significantly under-researched and ambiguous. For example, Turner (2012) argues that the introduction of Lean benefits employees due to improved skills development and greater increased involvement in process improvement decisions. Other scholars claim a negative impact on at least some managers and employees as a result of work intensification and disempowerment (AndersonConnelly, Grunberg, Greenberg, \& Moore, 2002; Carter et al., 2013; Grugulis \& Lloyd, 2010; Jones, Latham, \& Betta, 2013; Stewart et al., 2009; Torella, Falzon, \& Morais, 2012; Vidal, 2007).

It has become increasingly fashionable for managers and consultants to try to implement Lean, Six Sigma and similar innovations in service-based enterprises in a variety of industries and over the past decade, including in public services. Hence, it is timely to examine the impact of Lean and Six Sigma on the role of human resource management (HRM), the effective management of people and employee outcomes. It is especially appropriate to compare and contrast a range of approaches and employee experiences in different national and industry contexts. 
This special issue introduces international perspectives on attempts to implement lean thinking and its impact on HRM, skills, training, the design of work and outcomes for managers and other employees in a range of sectors and environments. The authors present a range of different views about Lean Six Sigma, which to an extent reflect their frame of reference. For example, most scholars from the field of operations management reflect a unitarist frame of reference (cf. Fox, 1974) and adopt a view that Lean is an array of neutral tools and techniques (e.g. Deming [1986] and his many disciples). Alternatively, critical social scientists adopt a more radical or pluralist frame of reference and may draw on labour-process analyses (e.g. Stewart \& Martinez, 2011). Such social scientists argue that Lean can be seen as an ideology - an attempt to increase management control over labour, rather than merely unambiguous and politically neutral tools and techniques. These different perspectives are represented in the articles in this special issue.

Furthermore, there is a dearth of published research on the nexus of HRM and process improvement, or on the role of HRM in relation to the implementation of process improvement, especially service-based contexts, despite the role of managers trying to ensure that people change their work practices and processes during Lean innovations. For example, little is known about the involvement of HRM specialists in the introduction of process improvement and on the implications in terms of HR policies and practices. The special issue seeks to address this gap in the literature. We initiate this by: first, discussing of the gaps in the literature on the relationship between Lean and HRM; second, summarising the research-based articles on Lean and HRM that are included in this special issue; and, third, proposing a future research agenda.

\section{HRM and Lean management}

We were motivated to propose this special issue as we were conducting research with other colleagues examining the impact on clinicians of the introduction of Lean management and Six Sigma processes into health-care organisations, particularly hospitals. We were interested not only in how process improvements were implemented, but also, importantly, in how managers and clinicians engaged in the implementation process, to what extent the process impacted on their work, the involvement, if any, of unions or professional organisations and the longevity of such improvements. We have also been exploring the involvement of HRM practitioners in the PR processes. We infer from the literature that there is a link between PR and HRM, including the implications for training and skills development, job design and role restructuring, and consultation and involvement processes (Bonavia \& Marin-Garcia, 2011; de Menezes, Wood, \& Gelade, 2010; Torella et al., 2012). There is considerable literature on the industrial relations and labour-process aspects of Lean, for example exploring the question as to whether Lean is about empowering or controlling workers, whether Lean tends to be associated with a unitarist rather than a pluralist approach, hence undermining unions and collective organisation (Jones et al., 2013; Parker \& Slaughter, 1995; Stewart et al., 2009), as well as the extent to which Lean seems to foster the engagement or exploitation of employees (Anderson-Connelly et al., 2002; Vidal, 2007).

However, we found little evidence in the literature on whether Lean was generally a strategic initiative of enterprises' senior leaders or the extent to which PR involved HRM at the highest levels of the enterprise. Similarly, we did not find substantial evidence that HR practitioners were generally included as partners in implementation or whether Lean Six Sigma is seen as part of a wider approach to managing change in terms of workplaces or organisational culture (Bonavia \& Marin-Garcia, 2011; de Menezes et al., 2010; Torella et al., 2012).

The majority of the research on process improvement focuses on the various techniques from an engineering, quality or operations management perspective (e.g. Deming, 1986; Plsek, 2013), rather than from HRM or people-related perspectives. However, others find that if Lean is to reduce impediments in the smooth flow of production through continuous improvement and elimination of wasted time and motion, workers should to be provided with the skills to help them 
control their work environment to achieve this (Torella et al., 2012). Among others, Bonavia and Marin-Garcia (2011) focussed attention on HRM factors in why Lean works or does not work. Moreover, de Menezes et al. (2010) argue that Lean involves a range of techniques that imply integration in the application of aspects of operations management and HRM.

Such ideas build on the work, for instance, of MacDuffie (1995) who examined bundles of HRM practices (i.e. internally consistent practices) in companies with different forms of work organisation. In particular, he focused on the organisational logic of 'flexible' production systems or 'lean production'. To MacDuffie (1995), flexible production systems include team-based work systems with high-commitment HRM practices, including contingent pay and an emphasis on training and involvement. He found that plants with flexible production systems consistently outperformed more traditional massproduction plants. He argued that Lean enriches HRM capabilities by, for example, further developing workforce skills.

More recent studies support these arguments. For instance, in a longitudinal study of British manufacturing firms, de Menezes et al. (2010) found that HRM practices, particularly those that empower or involve employees, support specific operations management practices and have a strong effect on performance. Furthermore, they concluded that a high degree of integration of operations management and HRM practices is linked with enhanced productivity. This study found that the integration of operations management and HRM is crucial to the success of quality improvement and Lean. They argued that genuine continuous improvement cannot be achieved without employee participation.

However, while MacDuffie (1995) and de Menezes et al. (2010) focus on productivity, other literature focuses on the impact of Lean on employees. Most of these authors were concerned with work organisation and job design, and were particularly critical of the impact of Lean on job satisfaction and the experience of work, characterising Lean as 'management by stress' (Graham, 1995; Parker \& Slaughter, 1995). Some also see Lean alongside other quality-management strategies (e.g. total quality management) as being an aspect of a union-marginalisation strategy. They hold that employees and their union representatives are co-opted into management thinking or an illusion whereby employees are made to feel that they are part of a participatory process, even though it has no real benefits for them (Jones et al., 2013; Stewart et al., 2009). Others point out that workplaces are complex environments and suggest those aspects of job re-engineering and workplace change induced by Lean might have different impacts and meanings on different groups of workers (Anderson-Connelly et al., 2002; Kashefi, 2009; Vidal, 2007).

In most such studies, when managerial prerogative and management strategies are mentioned, they are examined only briefly. Moreover, while HRM practices such as training or employee empowerment are identified, with the exception of MacDuffie's work and also Stewart et al. (2009), most others generally do not focus on HRM strategy, even though it is a component of managerial strategy.

It might be expected that the research literature on high-performance work systems (HPWS) practices and its increasing focus on employees (e.g. Bartram, Casimir, Djurkovic, Leggat, \& Stanton, 2012; Boxall, Ang, \& Bartram, 2011) would address HRM strategy and related issues. Building on MacDuffie's (1995) work, the HPWS field (with its emphasis on systems of work and bundles of practices such as empowerment, autonomy, training and development, and employment security) has much in common with the HRM practices identified in the studies of Lean (e.g. Birdi et al., 2008; Bonavia \& Marin-Garcia, 2011; Torella et al., 2012). Furthermore, de Menezes et al. (2010) argue that the 'choice of [HRM] practices is not driven by expectations on the performance of specific combinations [bundles], but by having an integrated system in place that reflects a managerial philosophy' (p. 13). It is not clear from many of these empirical studies whether the introduction of Lean Six Sigma is linked to a general managerial philosophy and strategy or whether Lean Six Sigma is seen as just another set of tools or another process to achieve limited goals. Also, it is rarely clear what is the role of HRM in the introduction and implementation of such methodologies. 
Nevertheless, it is evident from the literature that Lean ideas have been adapted from manufacturing contexts to a range of other industries such as health care and education, as governments sought more efficient and effective ways of providing services in a context of cost-containment policies and in the face of increased demand (Ben-Tovim et al., 2007; Kollberg et al., 2007). Interestingly, there does not seem to be a clear role that is generally adopted by HR practitioners when employing organisations try to implement Lean idea. Moreover, Lean is often introduced with no links or integration with key HRM functions such as employee performance appraisal (Leggat, Bartram, Stanton, Bamber, \& Sohal, forthcoming). Given the lack of research that comprehensively examines the relationship between Lean and HRM, we raise some important research questions: are HR practitioners part of the decision- making at the highest levels? To what extent are they seen as helpful facilitators - ensuring that there were no barriers to the introduction of major change projects? Or to what extent are they seen rather as the police force - making sure that no policies, practices, laws or agreements were crossed or breached? Or do HR practitioners seem to be bypassed, unless problems arise? The articles in this special issue cast light on such questions, but also raise further questions, which contribute to our proposed research agenda (towards the end of this article).

\section{The special issue}

Following on from this introduction, which is the first article in this special issue, the second one by Sparrow and Otaye-Ebede introduces some of the issues regarding the role of HRM architecture in sustaining lean improvements, especially as lean thinking extends from manufacturing and into the service sector. This is explored through 18 interviews with managers from 12 firms with a history of engagement in lean processes, including manufacturing and service industries. A key issue is the formation and location of centres of excellence in lean methods and process improvement knowledge. This issue emerges in particular in relation to the challenge of adapting lean approaches to the characteristics of service industries, which are different in several ways from manufacturing industries. This article suggests that in making these transitions, managers need to expand HR capabilities beyond traditional skills to include capability building, employee engagement in organisational and/or process changes, and managing relations between HRM specialists and line managers, as well as developing specific expertise in lean methodologies and their applications. Most of the HRM specialists in the firms studied lacked such expertise in lean. Therefore, Otaye-Ebede and Sparrow suggest that HRM leaders need to be more strategic in adjusting the role of HRM architecture in relation to its potential role in 'leaning' organisations.

In the third article, de Koeijer, Paauwe and Huijsman present a theoretically grounded framework that links Lean and Six Sigma, enabling HRM and important outcomes in health care. This framework contributes towards understanding of direct and indirect (moderating and mediating) effects related to Lean and Six Sigma in the context of health care. The authors argue that enabling HRM is crucial in creating mutual gains for both the enterprise and its employees. The general idea is that Lean and Six Sigma, combined with enabling HRM, foster employee well-being (happiness, health and relationships) and improved performance. The challenge is to go beyond the simple application of Lean and Six Sigma to develop a culture of continuous improvement. This article makes an important contribution to the HRM literature because it provides new insights into how HRM can be used to support process improvement initiatives and to enhance the potential benefits for employing organisations and their employees.

The fourth article by Stanton, Gough, Ballardie, Bartram, Bamber and Sohal (2014) analyses a process improvement project based on Lean and Six Sigma techniques in the Emergency Department (ED) of a large Australian hospital. Stanton et al. consider the perspectives of the clinicians, managers and other staff involved in the project implementation, implications for empowerment and work intensification within the ED. These authors find that the project appeared to improve patient flow from the ED to the wards and to have positive implications for some staff. 
However, these achievements tended to be the result of senior clinical staff using the project to leverage more resources and to create desirable outcomes, rather than specifically the result of using Lean methods. The authors also find some evidence of work intensification, but argue that this was attributable to wider systemic issues and budget constraints, rather than being a direct consequence of the use of Lean. Stanton et al. argue that translating Lean from a manufacturing context into the politicised and professionalised context of health care changes the usual questions about empowerment or work intensification to questions about the influence of powerful health- care stakeholders, including professional occupational groups.

The fifth article by Lindsay, Commander, Findlay, Bennie, Dunlop Corcoran and Van Der Meer examines the implementation of a Lean-type project in the UK's National Health Service. This is in the context of a public service underpinned by a new public management (NPM) regime undergoing financial austerity. The project centralised and automated the procurement and distribution of pharmacy supplies, while redesigning and redeploying pharmacy work closer to patients through ward- based satellite dispensaries. The research examined pharmacy employee experiences of consultation, implementation and outcomes of the work process changes, using surveys and interviews of stakeholders. The discussion of the project by managers was intersected by multiple rationalities: the rhetoric of NPM, the promises of Lean as enabling 'doing more with less', the aim to deliver better patient care and to provide more interesting jobs for staff by facilitating their skill and knowledge development, but without increases in costs or staffing.

The authors found that the pharmacy employees reported top-down implementation with only weak consultation with employees. Those staff redeployed reported more varied and interesting work, and having more control over job tasks than they had previously. Nevertheless, opportunities for training and progression were variable. While employees did not report any increase in top-down performance management, which has often been reported in relation to Lean, they did experience some work intensification in the context of tight levels of staffing.

The sixth article by Thirkell and Ashman examines Lean thinking in UK higher education. This is a novel approach because, while Lean-type approaches to process improvement have been implemented for more than a decade in hospitals, its introduction in higher education has been more recent. This article makes an important contribution to understanding some of the context-specific issues related to introducing Lean in universities. It also explores the potential for HRM specialists to play a role in supporting a broader culture change towards the potential for Lean thinking. Interviews with managers, administrative staff and academics from an 'old' university and a post-1992 ('new') university revealed significantly different understandings of what Lean is and how it could contribute to process improvement in their context. There was a shared view among managers and academics that the construction of academic freedom and the difficulties associated with measuring academic contributions and outputs are significant in limiting expectations that academics would support Lean approaches to changing their practices. The article questions the extent to which managers themselves practised Lean rather than merely espouse Lean. Respondents were dismissive of the potential for the HR departments to contribute to implementing Lean thinking. This dismissiveness reflected perceptions that HR departments play a key role in implementing staffing levels (with staff reductions commonly associated with Lean). In the 'new' university, the lack of empathy with the contextual relevance of Lean was demonstrated with the key training programme based on a visit to a car manufacturing plant. Despite some academics in business schools having knowledge about the use of Lean in other settings, it seems that they did not regard it as relevant to their own work as academics.

The seventh article by Proctor and Radnor re-examines data from a large research project that investigated the introduction of Lean process improvement into Her Majesty's Revenue and Customs Service (HMRC) in the UK, through the Pacesetter Program in 2006 -2007. The article focuses on the formation of teams and teamwork in relation to Lean efforts to increase the efficiency of HMRC. Drawing on qualitative data, the authors examine how teams emerged from different sites within 
HMRC, and with different effects within different teams and workers. While the authors partially corroborate other reports (Carter et al., 2011, 2013) of workers dissatisfaction with the deskilling, task simplification and standardisation that resulted from the introduction of Lean, they also seek to understand the alternative responses by some employees who reported some appreciation of Lean, especially the use of teamwork. While national-level site teams engaged in problem-solving that included the authority to make changes to standard operating protocols, at most HMRC sites teamwork was reinvented as workplace co-operation and information-sharing among employees with a primary aim of achieving operational targets. This distinguishes it from the use of teams in the Toyota Production System which operated as offline, problem-solving teams of workers with responsibilities from improving processes, and from socio-technical approaches to teamwork that emphasised problem-solving, autonomy and involvement in higher level decision-making. Radnor and Proctor consider this emerging use of teamwork in relation to the (generally) resourceconstrained (rather than demand-orientated) context of the public-service sector, and the way that teams operate to try to accomplish greater efficiency, as well as the tensions it can introduce into workplace relations.

The eighth article by Cullinane, Bosak, Flood and Demerouti also draws on quantitative data. It focuses on employees in a multinational pharmaceutical company, which has long used Lean. The authors examine the relationships between leanspecific job resources (active participation in day-to-day decision-making, performance feedback and training provisions), job demands (production pace, accountability, task interdependency) and employees' work engagement and their levels of exhaustion. They contribute to understanding the relations between job resources and demands. This article demonstrates that while lean-specific job demands, considered in isolation, can deplete the energy of employees, when combined with lean resources, Lean can also offer motivational challenges and increased work engagement. These results may help in interpreting the conflicting findings in the literature regarding the effects of Lean on employees. This work has implications for job design, highlighting the importance of adequate resources in ameliorating the potential negative effects of work pace, responsibility and worker interdependencies.

The final article by Bouville and Alis is based on an analysis of a large survey of employees across several employment sectors in France (the SUMER survey) to examine single and bundled Lean practices and their (statistical) relationships to reported job satisfaction, intention to leave and employee health. Despite claims that Lean can enhance employee health and job satisfaction, the relationship between Lean management, job redesign and employee outcomes is more complex than might be implied by any direct relationship. Bouville and Alis find that levels of responsibility, problem-solving, task standardisation and job rotation have significant negative effects on job satisfaction, intention to leave and/or employee health. These results are discussed in relation to the specific characteristics of Lean management. For example, this article highlights the rationale of job rotation that involves only a form of temporary replacement of workers, rather than one focused on multi-skilling and potential career advancement. The only Lean tool associated with better employee health in this sample was the presence of 'quality management'. Bouville and Alis make a contribution to understanding the connections between Lean and employees' job satisfaction and health. They also highlight the vital role that training plays in mediating the potential negative effects of increased role responsibilities.

\section{Conclusions: towards a research agenda}

A range of findings reported in this special issue have practical value for HRM practitioners and others who may be contemplating process improvement initiatives. These articles provide interesting insights into the relationships between process improvement innovations and HRM and outcomes for employees. At the end of this article, we start to infer an agenda for further research.

As observed, there has not yet been a substantial body of published research about how Lean techniques fit in practice with strategic HRM paradigms. To an extent, this 
reflects disciplinary boundaries and organisational 'silos'. Many enterprise leaders and others see Lean as the province of operations management, while many operations management specialists have little knowledge of the theory and practice of people management and notions of strategic HRM. For instance, the respondents reported in Thirkell and Ashman's article in this special issue were dismissive of the potential for HRM departments to contribute to implementing Lean. Therefore, we would encourage more research on the role of HRM specialists in the introduction of Lean and other performance-improvement innovations such as Six Sigma.

From the perspective of enterprise leaders who are aiming to implement process improvement, to what extent are HRM specialists perceived as part of the solution or part of the problem? In many cases, the latter prevails. How can HRM specialists try to change such perceptions? One promising avenue might be a reconsideration of the notion of HPWS. This notion attracts interest from operations management specialists, as well as from HRM specialists.

MacDuffie's work (1995) on bundles of HRM practices provides a useful starting point for considering the relationship between HPWS and Lean management, while de Koeijer- Gorissen et al. in this special issue outline a useful framework for analysis. This provides a helpful point of departure for further empirical studies that increase understanding of the relationship between HPWS and Lean.

Employers may have different HRM strategies and styles in relation to different occupational groups. For example, health-care organisations apply different management strategies and styles to their doctors in comparison to their catering staff, cleaners and maintenance engineers. This is because health-care leaders tend to see doctors as more important in strategic terms, so often defer to doctors. This raises a research topic: to what extent is implementing Lean approached in different ways for different occupational groups? Also how does Lean fit with different HRM strategies and styles, for example to what extent is it underpinned by commitment or control (cf. Bamber et al., 2009; Walton, Cutcher-Gershenfeld, \& McKersie, 2000).

The use of Lean extends far beyond manufacturing. As illustrated in this special issue, Lean is being applied in a range of other sectors including banking, call centres, health care, educational institutions, government agencies and other elements of the service sector. However, we need to know in more detail how Lean is being implemented and how is it being adapted in such different contexts? Is it a standard set of tools that can be used to fix short-term problems in a particular area or is it more about major cultural and organisational change? Again, what is the role of HRM specialists in these change processes?

There is much research in a labour-process paradigm on the outcomes of Lean process improvement on employees. However, there has been comparatively little published research on this topic conducted in an HRM paradigm. Accordingly, we advocate more research to consider what is the impact of process improvement on employees (and managers), in particular, to consider such issues as work intensification, workplace employment relations, occupational health and safety. To what extent is Lean used to empower workers and managers or does it inevitably lead to work intensification?

Despite substantial research on Lean in a labour-process paradigm on Lean management (e.g. Anderson-Connolly et al., 2002; Stewart \& Martinez, 2011; Stewart et al., 2009), there has been comparatively little research on Lean in an employmentrelations paradigm. Many enterprises that try to implement Lean are unionised. Consequently, it is important to conduct more research in an employment-relations paradigm which should be informed by the following questions: what is the relationship between Lean and collective and individual bargaining, unions, voice and contracts of employment? To what extent are unions involved in the implementation of Lean and is Lean used to undermine unionism?

It seems that Lean approaches are implemented successfully by car makers (e.g. Toyota, Nissan, Honda and Mazda) in Japan, which in the terms of Hall and Soskice (2001) is a form of coordinated market economy. But to what degree is it necessary for Lean approaches to be substantially modified for them to be implemented successfully in other contexts, for instance hospitals, government 
agencies and universities in western liberal market economies, again in the terms of Hall and Soskice (2001)? In which ways and how are Lean approaches modified in such other contexts? It would be worth considering these questions also in various national, regional and sectoral contexts. This would help researchers to generalise their findings.

We hope that the articles in this special issue will lead to further developments of the issues raised in their conclusions and also in the suggestions above. We look forward to continuing debate on these important issues.

\section{Acknowledgements}

We acknowledge with thanks other members of the research team: Richard Gough, Sandy Leggat and Amrik Sohal. We thank the current and former editors of the IJHRM for accepting our proposal for this special issue. We are grateful to all of the people who submitted papers for this special issue. We also thank the people who refereed on a double-blind basis the papers that are included and those that were not included in this special issue.

\section{Funding}

Relevant research by the authors was supported under Australian Research Council's Linkage Projects funding scheme (project number LP110200528).

\section{References}

Anderson-Connolly, R., Grunberg, L., Greenberg, E., \& Moore, S. (2002). Is Lean mean?: Workplace transformation and employee well-being. Work Employment and Society, 16, 389412.

Arnheiter, E. D., \& Maleyeff, J. (2005). The integration of lean management and Six Sigma. The TQM Magazine, 17, 518.

Bamber, G. J., Gittell, J. H., Kochan, T. A., \& von Nordenflytch, A. (2009). Up in the air: How airlines can improve performance by engaging their employees. Ithaca, NY: Cornell University Press.

Bartram, T., Casimir, G., Djurkovic, N., Leggat, S., \& Stanton, P. (2012). Do perceived high performance work systems influence the relationships between emotional labor, burnout and intention to leave? A study of Australian nurses. Journal of Advanced Nursing, 68, 15671578.

Ben-Tovim, D. I., Bassham, J. E., Bolch, D., Martin, M. A., Dougherty, M., \& Szwarcbord, M. (2007). Lean thinking across a hospital: Redesigning care at the Flinders Medical Centre. Australian Health Review, 31, 1015.

Birdi, K., Clegg, C., Patterson, M., Robinson, A., Stride, C. B., Wall, T. D., \& Wood, S. (2008). The impact of human resource and operation management practices on company productivity: A longitudinal case study. Personnel Pyschology, 61, 467501.

Bonavia, T., \& Marin-Garcia, J. (2011). Integrating human resource management into Lean production and their impact on organisational performance. International Journal of Manpower, 32, 923938.

Boxall, P., Ang, S., \& Bartram, T. (2011). Analysing the black box of HRM: Uncovering HR goals, mediators and outcomes in a standardized service environment. Journal of Management Studies, 48, 15041532.

Carter, B., Danford, A., Howcroft, D., Richardson, H., Smith, A., \& Taylor, P. (2011). Lean and mean in the civil service: The case of processing in HMRC. Public Money \& Management, 31, 115122.

Carter, B., Danford, A., Howcroft, D., Richardson, H., Smith, A., \& Taylor, P. (2013). Stressed out of my box : Employee experience of lean working and occupational ill-health in clerical work in the UK public sector. Work, Employment \& Society, 27, 747767.

de Menezes, L., Wood, S., \& Gelade, G. (2010). The integration of human resource and operation management practices: A longitudinal case study. Journal of Operations Management, 28, 455 471.

Deming, W. E. (1986). Out of the crisis. Cambridge: MIT Press.

Fox, A. (1974). Beyond contract: Work, power and trust. London: Faber.

Graham, L. (1995). On the line at Subaru-Isuzu: The Japanese model and the American worker. Ithaca, NY: Cornell University Press.

Grugulis, I., \& Lloyd, C. (2010). Skill and the labour process: The conditions and consequences of change. In P. Thompson \& C. Smith (Eds.), Working life: Renewing labour process analysis (pp. 91 112). Houndmills: Palgrave Macmillan.

Hall, P. A., \& Soskice, D. (Eds.). (2001). Varieties of capitalism: The institutional foundations of comparative advantage. Oxford: Oxford University Press. 
Holweg, M. (2007). The genealogy of lean production. Journal of Operations Management, 25, 420437.

Jones, R., Latham, J., \& Betta, M. (2013). Creating the illusion of employee empowerment: Lean production in the international automobile industry. The International Journal of Human Resource Management, 24, 16291645.

Kashefi, M. (2009). Job satisfaction and/or job stress: The psychological consequences of working in high performance work organisations . Current Sociology, 57, 809828.

Kollberg, B., Dahlgaard, J. J., \& Brehmer, P.-O. (2007). Measuring lean initiatives in health care settings: Issues and findings. International Journal of Productivity and Performance Management, 56, 7 24.

Lean Enterprise Australia. (n.d.). What is Lean? Retrieved May 24, 2014, from www.lean.org.au

Leggat, S. G., Bartram, T., Stanton, P., Bamber, G., \& Sohal, A. (Forthcoming). Have process redesign methodologies been successful in changing employee practices to improve the processes of care delivery in public hospitals? A systematic review. Public Money and Management.

Linehart, J., Huxley, C., \& Robertson, D. (1997). Just another car factory? Lean production and it discontents. Ithaca, NY: Cornell University Press.

MacDuffie, J. (1995). Human resource bundles and manufacturing performance: Organisational logic and flexible production systems in the world auto industry. Industrial and Labor Relations Review, 48, 197221.

Ohno, T. (1978). Toyota production systems: Beyond large scale production. Tokyo: Diamond.

Parker, M., \& Slaughter, J. (1995). Unions and management by stress. In S. Babson (Ed.), Lean work: Empowerment and exploitation in the global auto industry (pp. 41 53). Detroit, MI: Wayne State University Press.

Plsek, P. E. (2013). Accelerating health care transformation with Lean and innovation: The Virginia Mason experience. Boca Raton, FL: CRC Press.

Shadur, M. A., Rodwell, J. J., \& Bamber, G. J. (1995). Factors predicting employees acceptance of lean production. Human Relations, 48, 14031425.

Shah, R., Chandraskeran, A., \& Linderman, K. (2008). In pursuit of implementation patterns: The context of Lean and Six Sigma. International Journalof Production Research, 46, 66796699.

Stanton, P., Gough, R., Ballardie, R., Bartram, T., Bamber, G. J., \& Sohal, A. (2014). Implementing lean management/Six Sigma in hospitals: Beyond empowerment or work intensification? The International Journal of Human Resource Management, 25, 2926 2940, this issue.

Stewart, P., \& Garrahan, G. (1995). Employee responses to new management techniques in the auto industry. Work, Employment and Society, 9, 517536.

Stewart, P., \& Martinez, L. M. (2011). Collective narratives and politics in the contemporary study of work: The new management practices debate work. Employment and Society, 25, 327341.

Stewart, P., Murphy, K., Danford, A., Richardson, T., Richardson, M., \& Wass, V. (2009). We sell out time no more: Workers struggles against Lean production in the British car industry.

London: Pluto Press.

Taylor, F. W. (1911). Shop management. New York, NY/London: Harper and Brothers.

Torella, M. S., Falzon, P., \& Morais, A. (2012). Participatory design in Lean production: Which contribution from employees? For what end? Work, 41, 27062712.

Turner, C. M. (2012). Implement a Lean management system: Create change through improvement. North Charleston, SC: Createspace.

Vidal, M. (2007). Lean production, worker empowerment and job satisfaction: A qualitative analysis and critique. Critical Sociology, 33, 247278.

Walton, R. E., Cutcher-Gershenfeld, J. E., \& McKersie, R. B. (2000). Strategic negotiations. Ithaca, NY: Cornell University Press.

Womack, J., \& Jones, D. (2003). Lean thinking. London: Simon \& Schuster.

Womack, J. P., Jones, D., \& Roos, D. (1990). The machine that changed the world. New York, NY: Harper. 